\title{
EMPLOYER BRAND OF CHOICE: AN EMPLOYEE PERSPECTIVE
}

\section{Victoria BELLOU ${ }^{1}$, Ioannis CHANIOTAKIS ${ }^{2}$, Ioannis KEHAGIAS ${ }^{3}$, Irini RIGOPOULOU ${ }^{4}$}

\author{
${ }^{1}$ Department of Economic Studies, University of Thessaly, 43, Korai Str, 38333 Volos, Greece \\ ${ }^{2}$ Piraeus Bank,170, Alexandras Ave. 11521 Athens, Greece \\ ${ }^{3}$ Hellenic Open University, 18, Parodos Aristotelous Str, 26 335, Patra, Greece \\ ${ }^{4}$ Athens University of Economics and Business, 76, Patission Str. GR-10434, Athens, Greece \\ E-mails: 1vbellou@uth.gr (corresponding author); ${ }^{2}$ ichaniotakis@yahoo.gr; \\ 3jkehagias@eap.gr; ${ }^{4}$ erigop@aueb.gr
}

Received 22 March 2013; accepted 20 September 2013

\begin{abstract}
This study seeks to contribute in the field of the ideal employer, by determining the Employer Brand of Choice and its core components. In doing so, a pilot study was initially conducted to delineate these components. Evidence from 896 working adults that participated in a field study support the multi-dimensionality of the construct Employer Brand of choice, highlighting the role of "Remuneration", "Relationships", "Opportunities for Self Development", "Recognition", and "Corporate Image". These findings not only offer a concrete and holistic theoretical base of Employer Brand of Choice, but they can also serve as a managerial guide towards enhancing companies' ability to attract, retain and motivate talented individuals.
\end{abstract}

Keywords: Employer Brand, Employer Brand of Choice, Employer of Choice, organisational identity, psychological contract, organisational attractiveness.

JEL Classification: M54, M310.

\section{Introduction}

Consumers are in constant search for suitable products, choosing brands that best meet their preferences. Evidence suggests that individuals they tend to behave in a similar manner when they are in a position of choosing an employer or switching employers. Employees can develop closer relationships with employers, just like consumers do with product brands (Ambler, Barrow 1996). Along these lines employers can be seen as corporate brands possessing traits equivalent to those that characterise product brands. Consequently, when companies announce job openings, applicants prefer those companies that are closer to what they regard as an Ideal employer. At the same time, the product brand is considered to be a critical source of sustainable competitive advantage (Fernandez-Lores et al. 2015) and employees are seen as an integral part of the company effort to develop strong brands by creating value in consumers' minds (de Chernatony, 
Dall'Olmo Riley 1999). In such a context, developing corporate and product brands that are superior to those of competition calls for showing an active interest in employees, both existing and potential (Barrow, Mosley 2005).

To stress that companies should become more people oriented, both internally and externally, Ambler and Barrow (1996) introduced the term "Employer Brand" (EB). According to the authors, EB refers to all the benefits offered by a certain company to its employees, which create a unique identity in the eyes of employees and applicants and make them willing to stay with or join this company. This shift to understanding of corporations can be explained by the fact that organisations have two important factors: their brands and their employees (Hochegger, Terlutter 2012). A term used interchangeably in the literature, causing misconceptions is that of Employer of Choice (EOC). EOC refers to the employer who, by possessing of attractive attributes, can attract the most talented employees. Thus, although any company with a distinctive promise can become an EB, not any company can claim to be an EOC. Moreover, an EB might be attractive as well as not attractive to some potential employees. On the contrary, the EOC embodies a certain level of attractiveness, and asserts the title of the most attractive employer by a significant portion of potential employees, and more importantly, by the more talented ones. So, since attractiveness has been recognised as a valuable asset of modern companies (Wilden et al. 2010), our aim is to fill this gap, by combining those two constructs in a new one, the "EB of Choice". Valuing both the practical and theoretical value of EB and EOC, this study differs from previous ones in that it proposes and adopts a holistic approach. Furthermore, it emphasizes the entire spectrum of needs that an employee aims at fulfilling through employment, thus determining the profile of the preferred distinctive employer. By doing so, the contribution of the work reported here advances the existing literature and thinking one step ahead, by identifying the components of the EB of Choice. Thus, the main issue that this study departs to explore is how employees choose an employer, by recognizing the criteria that are of outmost importance in their eyes. Besides, this should be the starting strategy point for companies who seek to be the winners in the "war of talent" (Williams 2000).

Consequently, the present research aims to extent the related to the Ideal employer line of research. Our research builds on the proposition that neither the EB nor the EOC alone is sufficient to provide the answer to this "war of talent" among companies. Hence, our overall objective is to obtain a deeper understanding of how important variables originated by those two streams of thought, variables like psychological contract, organizational attractiveness, or organizational identity, can holistically utilized in the context of a new concept. Our proposition lies on the fact that important concepts and thinking originated by the marketing field was remaining until now unexplored, thus by filling this gap, the new proposed "EB of Choice" construct is being introduced. 


\section{Literature review}

\subsection{Employer Brand and Employer of Choice}

EB is a relatively new term in the brand management lexicon. Yet, several definitions have been offered. Ambler and Barrow (1996: 187) introducing the term referred to "the functional, economic and psychological benefits that are provided by employment, and identified with the employing company." Based on this approach, Backhaus and Tikoo (2004) argued that EB presents a "value proposition" that individuals believe they will receive in terms of benefits and work-related terms and conditions when working for a specific employer. According to the Conference Board (2001: 3), EB "establishes the identity of the firm as an employer. It encompasses the firm's value system, policies and behaviours toward the objectives of attracting, motivating, and retaining the firm 's current and potential employees." In this definition the Conference Board takes on a more resource-based view which the company can adopt in order to address itself to potential employee audiences. In this identity establishing process, Mangold and Miles (2007: 424) recognise the role of current employees as central, since according to their definition, EB is "the image presented to an organisation's customers and other stakeholders through its employees".

Taken together, EB has been understood as the package of the benefits provided by an employer, playing the role of identifiers of a particular employer. These benefits aim at establishing a distinctive personality and identity of the company as an employer. The benefits derive from company's values, systems and policies or, expressing it differently, encompasses the attitudes as well as behaviours pertaining in the working environment. Though some argue that EBs, as in any other brand version, aim at becoming not only distinctive but also attractive, one should clarify that according to core marketing theories and perspectives, attractiveness is a targeted and therefore not a universal imperative. This is the reason why, one should avoid generalizations, claiming that an EB is identical to the "greatest place to work". Along this line, the EOC construct reflects an employer who inspires highly talented workers to join them and stay with them. As clearly defined by Herman and Gioia, EOC is "an employer of any size in the public, private or not-for-profit sector that attracts, optimises and holds top talent for long tenure... because the employees choose to be there" (2000: xi).

Consequently, the main result of treating employers as brands is their association with a distinctive personality and identity. This view is in line with the Conference Board view (2001) that clearly proposed that the EB establishes the identity of a firm as an employer, as Backhaus and Tikoo claim (2004). In line with the above, several empirical studies so far, confirm that corporate positioning, internal branding, EB and related practices could be successful avenues for companies (Elving 2013). Borrowing again from core marketing theories, brands are seen as promises (Montes, Zweig 2009). On this basis, a central issue in branding concerns the confirmation of the promises that were given before of the establishment of the relationship between the brand and its customers. As a consequence, a central notion of branding is the pursuit of the best possible match between the two parties involved (the product brand and its potential 
customers, the corporate brand and its targeted stakeholders, the EB and its current as well as prospect employees).

In fact, researchers have put psychological contract and organisational identity at the heart of EB and EOC (Edwards 2009; He, Balmer 2013). The psychological contract refers to "...individual's beliefs regarding the terms and conditions of a reciprocal exchange agreement between the person and another party..." (Bellou 2007: 68) and prefigures both the quality of the employment relationship for current employees and the image of the expected quality of the employment relationship for potential employees. Examining the psychological contract from an employee perspective, this agreement is built upon the real and expected benefits that every single individual considers to be important, based on his/her own personal needs (Rousseau 1989). Just as brands are seen as promises linked to the characteristics of the product (Kapferer 2004), the psychological contract constitutes a promise concerning the employment relationship.

As for organisational identity, according to Dutton et al. (1994), it refers to the cognitive connection that exists between the identity of an organisation, and the identity an individual applies to himself or herself. Organisational identification has its basis on social identity theory, referring to the incorporation of the group's norms and values into the individual's self-concept (Tajfel, Turner 1986). Since organisational identification is a form of social identification, an individual's social identity is enhanced when the group to which he or she belongs is distinctive and more favourable than that of comparable groups (Ashforth et al. 2008).

Consequently, and following the marketing paradigm which is based on, driven by and focused on customer needs, companies seek to find ways to attract potential employees and retain the existing ones, just like they try to retain existing customers and attract new customers to their product brand. To do so, companies are seeking the best possible 'fit' between their own identity and personality and those of prospective employees. When this process is successfully implemented, the expected and desired outcome for the company is to become the preferable EB, which means that prospective and current employees share a common belief, that this company is an EOC (Branham 2005). Since the borders between EB and EOC are not always easy to discern, we suggest another construct to combine both, called "EB of Choice". In line with previous researchers, we claim that in order to become an EB of Choice, the company should become a distinguishable employer, connected to those benefits and employment brand-related predictors (Edwards, Edwards 2013) that are the most important among the prospect and the current employees.

\subsection{Measuring Employer Brand of Choice}

Recent research efforts that have adopted different approaches to measure EB and EOC fall into three groups. First, Davies et al. (2004), Slaughter et al. (2004) and Davies (2008) emphasized the need for reflecting the company's personality and the extent to which employees believe that they fit that personality. Along the same lines, Lievens and his colleagues (i.e. Lievens 2007; Lievens et al. 2007) adopted symbolic and instrumental attributes to assess the EB of specific organisations. This approach clearly emphasized the organisational identity part of EB. 
Second, as Sutherland et al. (2002) argued, the best applicants will choose the best company among a few, after comparing them in terms of corporate culture and practices. Organisational culture refers to the attitudes, beliefs, values and consequently to the experiences that concur, or are expected to concur, in a particular company. This point of view is in line with the broader meaning of the sociological construct of "culture" and implies that organisational culture is not only important to job maintenance but also to job choice (Mosley 2007; Backhaus Tikoo 2004). Again, this perspective of EB emphasizes individuals' needs for organisational identification with their current or future employer.

Third, Ambler and Barrow (1996) and Berthon et al. (2005) stressed the importance of benefits sought and assessed organisational attractiveness. Organisational attractiveness occurs when the shared values and beliefs create a set of accepted norms and consequently of accepted behaviours in the organisation's life (Koberg, Chusmir 1987). Thus, as Berthon et al. (2005: 156) propose: “...Employer attractiveness is defined as the envisioned benefits that a potential employee sees in working for a specific organisation ...". Contrary to the previous perspectives, this approach emphasizes benefits as the underlying criterion of employer choice. More specifically, Ambler and Barrow (1996) conducted semi-structured interviews to support their view that EB is important for both marketers and HR practitioners and created three benefit categories (functional, economic, and psychological) which are critical but not sufficient in describing the complexity of the employment relationship in the eyes of applicants and existing employees. On the other hand, Berthon et al. (2005) asked participants to identify the profile of the Ideal employer based on what is important to them when considering potential employers, what they would dislike in a work setting, how they tend to gather job related information and concluded with what makes an employer attractive. Similarly, other scholars like Jain and Bhatt (2014) contributed also on the understanding of EBing through the eyes of the potential employees in their countries.

Believing that neither benefits and organisational identity (emphasizing EB) nor attractiveness (emphasizing EOC) can be overlooked when examining the profile of the EB of Choice, this study goes a step further than previous approaches, by taking into consideration all three. In addition, to our best of knowledge, there are no prior attempts incorporating large representative samples of employees. In fact, the existing research is based on large and widely spread sample whereas Lievens et al. (2007) examined EOC in terms of job and organisational attributes in a very particular (army) setting, Berthon et al. (2005) followed qualitative (focus groups) methodology to discuss employer attractiveness, Davies et al. (2010) used in depth interviews to investigate EB and Knox and Freeman (2006) have dealt with the EB image by interviewing students with no work experience.

\section{Research methodology}

Since the relative importance of benefits and organisational characteristics lies in the eyes of individuals, it was considered essential that they directly identify what they seek from their current or prospective employer, if they are to consider it as the best 
alternative and prefer it over other choices. Given that both EB and EOC are still under-explored, a pilot qualitative methodology was initially adopted through in-depth personal interviews with HR executives of large organisations, both domestic and multinationals, operating in different industries. The findings from those interviews were used in a confirmatory and complementary way to the previously utilised scales. The various benefits and characteristics identified through the literature review formed the basis for the discussion guide used in the interviews.

To illustrate the above findings, we synthesised the views of the executives and developed a conceptual framework of "EB of Choice" (depicted in Fig. 1), including the variables of "salary" (REM), "added benefits" (BEN), "self development" (SD), "relationships with manager" (RELM), "relationships with colleagues" (RELC), "recognition" (REC), "commercial image" (CI) and "social image" (SI).

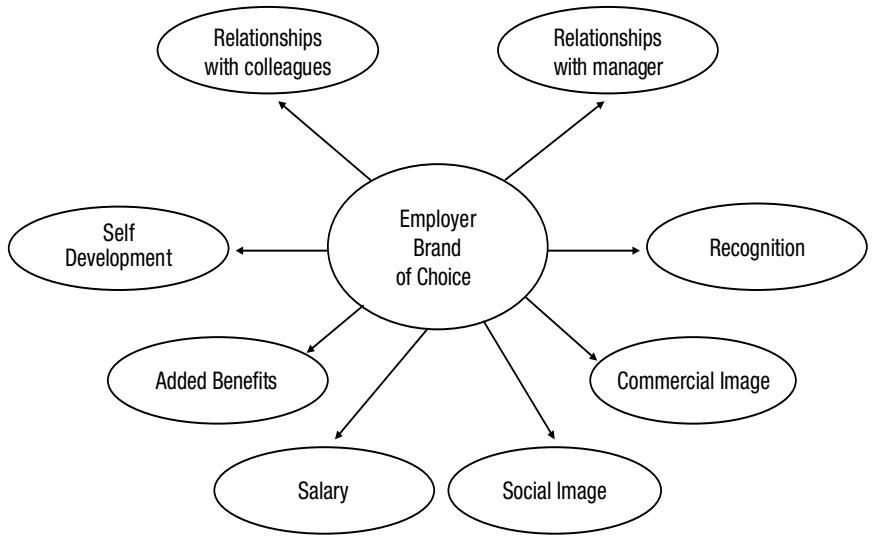

Fig. 1. The conceptual framework

As a result, initially, a set of 42 distinctive items was created, based on existing instruments on psychological contract (Bellou 2007), organizational identity (O'Reilly III et al. 1991) and attractiveness (Berthon et al. 2005; Rampl, Kenning 2014). Then, 12 semi-structured interviews were conducted where the main topic was to discuss and confirm the most important benefits and organisational characteristics that prospective employees value in their relationship with an employer with a distinctive personality. Finally, we compared the responses of HR executives with the list of items developed based on previous instruments and came up with 48 items that formed our questionnaire, measured the level of importance that employees place on a series of benefits for employees and organizational characteristics that the ideal employer should compile.

All 3500 students following a distance learning Business Administration course at the Hellenic Open University were approached electronically using online survey software and 896 replies were received, securing a $25.6 \%$ response rate. The responses from 36 respondents without any working experience were excluded from the analysis. 


\section{Results}

As findings suggest, no dimension has a dominant impact on the preferred EB construct, thus highlighting the multi-dimensionality of the EB of Choice construct. More precisely, during the first stage of data analysis, a number of tests for the measurement of reliability and validity were performed. As seen in Table 1, in accordance with Hair et al. (2009), all measurement scales of the latent variables were found to be reliable.

Table 1. Reliability analysis of measurement scales

\begin{tabular}{lccc}
\hline \multicolumn{1}{c}{ Latent variable } & $\begin{array}{c}\text { Alpha } \\
\text { Cronbach }\end{array}$ & $\begin{array}{c}\text { Average variance } \\
\text { extracted (AVE) }\end{array}$ & $\begin{array}{c}\text { Composite } \\
\text { reliability (CR) }\end{array}$ \\
\hline Salary (REM) & 0.7384 & 0.64 & 0.73 \\
\hline Added benefits (BEN) & 0.8933 & 0.67 & 0.78 \\
\hline Self development (SD) & 0.7723 & 0.55 & 0.77 \\
\hline Relationships with manager (RELM) & 0.7538 & 0.65 & 0.87 \\
\hline Relationships with colleagues (RELC) & 0.7650 & 0.75 & 0.80 \\
\hline Recognition (REC) & 0.8442 & 0.64 & 0.87 \\
\hline Commercial image (CI) & 0.8133 & 0.54 & 0.73 \\
\hline Social image (SI) & 0.8281 & 0.65 & 0.75 \\
\hline
\end{tabular}

Furthermore, the results for discriminant validity are presented in Table 2. By checking the intervals of the correlation estimates \pm two standard errors for any two factors, it is evident that the value 1.0 is not included, so that discriminant validity is established.

The research model was specified in a structural model and tested using the Amos 16.0 software and the maximum likelihood method. After the appropriate modifications the final model was extracted (shown in Fig. 2). More specifically, in order to achieve an acceptable model, three new latent variables (second order) were added, namely:

- "Remuneration", which is measured with "salary" and "added benefits",

- "Relationships", which is composed of the "relationships with manager" and the "relationships with colleagues", and

- "Corporate Image", which was measured through "commercial image" and "social image".

As presented in Table 3, although $\chi^{2}$ statistics did not show a good fit of the model, this was to be expected because the sample size was above 200 (actually 896 respondents) (Schumacker, Lomax 2004). Nevertheless, the final model was considered to be acceptable, as, in line with Hoyle and Panter (1995), all other indicators of the model fit were acceptable (Table 3). Moreover, all proposed relationships were supported by the significant path coefficients estimated in the model, as indicated in Figure 2. 
Table 2. A summary of discriminate validity analyses

\begin{tabular}{ccccccc}
\hline \multicolumn{2}{c}{ A pair of latent variables } & Correlation estimate & Correlation estimate + - two standard errors \\
\hline REC & $<-->$ & REM & 0.472 & $(0.410$ &, & $0.534)$ \\
\hline REM & $<-->$ & RELC & 0.430 & $(0.392$ &, & $0.468)$ \\
\hline BEN & $<-->$ & REM & 0.524 & $(0.416$ &, & $0.632)$ \\
\hline RELM & $<-->$ & REM & 0.406 & $(0.364$ &, & $0.448)$ \\
\hline SD & $<-->$ & REM & 0.512 & $(0.446$ &, & $0.578)$ \\
\hline REM & $<-->$ & CI & 0.304 & $(0.230$ &, & $0.378)$ \\
\hline REM & $<-->$ & SI & 0.231 & $(0.157$ &, & $0.305)$ \\
\hline REC & $<-->$ & RELC & 0.904 & $(0.854$ &, & $0.954)$ \\
\hline REC & $<-->$ & BEN & 0.367 & $(0.277$ &, & $0.457)$ \\
\hline REC & $<-->$ & RELM & 0.931 & $(0.875$ &, & $0.987)$ \\
\hline REC & $<-->$ & SD & 0.910 & $(0.832$ &, & $0.988)$ \\
\hline REC & $<-->$ & CI & 0.488 & $(0.410$ &, & $0.566)$ \\
\hline REC & $<-->$ & SI & 0.477 & $(0.399$ &, & $0.555)$ \\
\hline BEN & $<-->$ & RELC & 0.369 & $(0.313$ &, & $0.425)$ \\
\hline RELM & $<-->$ & RELC & 0.877 & $(0.843$ &, & $0.911)$ \\
\hline SD & $<-->$ & RELC & 0.884 & $(0.836$ &, & $0.932)$ \\
\hline RELC & $<-->$ & CI & 0.508 & $(0.460$ &, & $0.556)$ \\
\hline RELC & $<-->$ & SI & 0.504 & $(0.454$ &, & $0.554)$ \\
\hline BEN & $<-->$ & RELM & 0.311 & $(0.247$ &, & $0.375)$ \\
\hline BEN & $<-->$ & SD & 0.433 & $(0.337$ &, & $0.529)$ \\
\hline BEN & $<-->$ & CI & 0.386 & $(0.266$ &, & $0.506)$ \\
\hline BEN & $<-->$ & SI & 0.387 & $(0.263$ &, & $0.511)$ \\
\hline RELM & $<-->$ & SD & 0.831 & $(0.779$ &, & $0.883)$ \\
\hline RELM & $<-->$ & CI & 0.393 & $(0.341$ &, & $0.445)$ \\
\hline RELM & $<-->$ & SI & 0.382 & $(0.328$ &, & $0.436)$ \\
\hline SD & $<-->$ & CI & 0.498 & $(0.420$ &, & $0.576)$ \\
\hline SD & $<-->$ & SI & 0.491 & &, & $0.573)$ \\
\hline CI & $<-->$ & SI & 0.481 & & & $0.583)$ \\
\hline & & & & & & \\
\hline
\end{tabular}

Based on the model, as seen in Figure 2, it is confirmed that the "EB of Choice" is positively affected by "Remuneration", "Relationships", "Opportunities for Self Development", "Recognition" and "Corporate Image" in the sense of Commercial Image and Social Image. In comparison to the previous research discussed, our model offers a more concrete though also multi-faceted analytical base. So, apart from the monetary rewards and the additional benefits that constitute the "Remuneration" dimension, as one group of benefits that employees attribute to the EB of Choice, all the remaining dimensions could be broadly entitled "Relationships". More precisely, employees value:

a) inter-personal relationships within the company distinguishing horizontal from vertical relationships among employees,

b) the relationship between the company as an entity and the person/employee,

c) the relationship of the employer company to the society/community. 


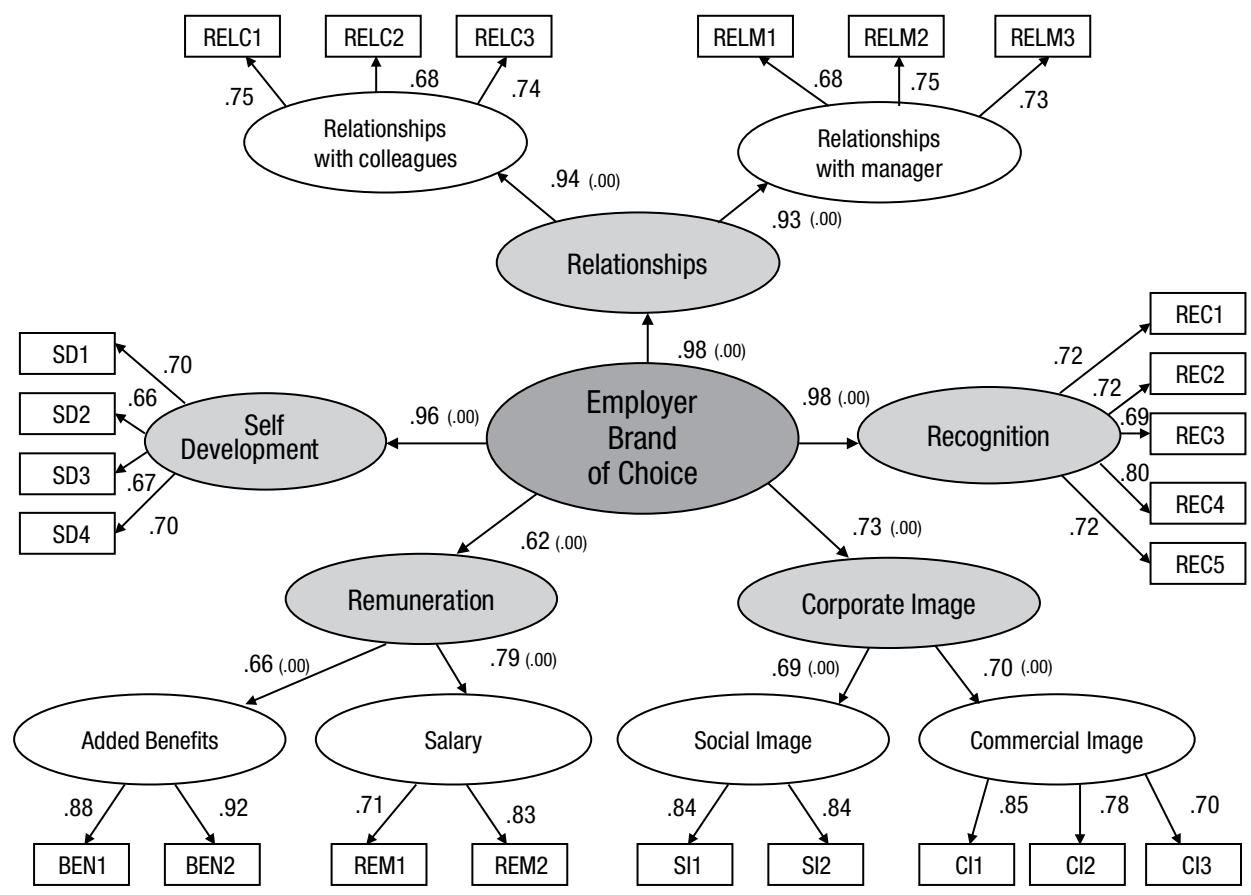

Fig. 2. The EB of Choice model

Table 3. Summary of fit indices of the model

\begin{tabular}{ccccccccccc}
\hline Fit indices & $\chi^{2}$ & p. & $\chi^{2} /$ d.f. & GFI & AGFI & NFI & IFI & TLI & CFI & RMSEA \\
\hline Value & 827.181 & .000 & 3.432 & .925 & .907 & .925 & .945 & .937 & .945 & .052 \\
\hline Sug. value & & $>.05$ & $<3.00$ & $>.90$ & $>.90$ & $>.90$ & $>.90$ & $>.90$ & $>.95$ & $<.07$ \\
\hline
\end{tabular}

Notes: $\chi^{2} /$ d.f. ratio $<2$ (Marsh, Hocevar 1985), GFI $>0.90$, AGFI $>0.90$, NFI, IFI, TLI $>0.90$ (Hair et al. 1998), CFI > 0.95 (Hu, Bentler 1999), RMSEA < 0.07 (Hair et al. 2006).

\section{Discussion of findings}

The study is among the first to empirically test determinants of aspects related to both, EB and EoC. Based on theoretical considerations which prove weaknesses and limitations regarding these prior views in isolation, we sought to derive a more holistic concept that takes into consideration the differences as well as the complementarity of the two prior concepts, using data from a large-scale empirical study to empirically support our proposition. The findings of the present study are of both theoretical and practical value. From a theoretical perspective, in line with Edwards' (2009) approach, the relationship between a company and its employees must be supported by several pylons in the form of offered benefits and company characteristics.

The introduction of the concept "Brand" intended to differentiate the product, the corporation, the idea or even the human being of reference. Although differentiation is still the essence of branding (Aaker 2003), if this is not related to aspects of superiority, 
Table 4. EB of Choice - exact statements / dimensions

\begin{tabular}{|c|c|}
\hline \multicolumn{2}{|r|}{ SELF DEVELOPMENT } \\
\hline SD1 & The company has learning orientation \\
\hline SD2 & Career coaching and advice is provided \\
\hline SD3 & The dissemination of knowledge is emphasized \\
\hline SD4 & There is clear emphasis on the development of skills \\
\hline \multicolumn{2}{|r|}{$\begin{array}{l}\text { CORPORATE IMAGE } \\
\text { Commercial image }\end{array}$} \\
\hline \multicolumn{2}{|c|}{ CI1 The company is financially solid } \\
\hline \multicolumn{2}{|c|}{ CI2 The company develops innovative products and services } \\
\hline \multicolumn{2}{|c|}{ CI3 The company is market oriented } \\
\hline \multicolumn{2}{|r|}{ Social image } \\
\hline \multicolumn{2}{|c|}{ SI1 The company is sensitive to social issues } \\
\hline \multicolumn{2}{|c|}{ SI2 The company is oriented towards protection of the environment } \\
\hline \multicolumn{2}{|r|}{ RECOGNITION } \\
\hline REC1 & The new hires feel welcome and important \\
\hline REC2 & The creativity of the employees is recognised and utilised \\
\hline REC3 & Management realizes and recognises the overall contribution of the employees \\
\hline REC4 & The employees feel important and identifiable \\
\hline REC5 & The employees are given the opportunity to apply their theoretical Knowledge \\
\hline \multicolumn{2}{|r|}{$\begin{array}{c}\text { RELATIONSHIPS } \\
\text { Relationships with colleagues }\end{array}$} \\
\hline RELC1 & The active and factual interest among colleagues is reinforced \\
\hline RELC2 & Employees are showing mutual respect \\
\hline RELC3 & There is sincere communication among employees \\
\hline \multicolumn{2}{|r|}{ Relationships with managers } \\
\hline RELM1 & Management provides proper guidance to employees \\
\hline RELM2 & Management is practicing meritocracy \\
\hline RELM3 & Managers recognise the efforts of their subordinates \\
\hline \multicolumn{2}{|r|}{$\begin{array}{l}\text { REMUNARATION } \\
\text { Extra benefits }\end{array}$} \\
\hline BEN1 & Supplementary health insurance is offered \\
\hline BEN2 & Supplementary pension scheme is offered \\
\hline \multicolumn{2}{|r|}{ Salary } \\
\hline REM1 & Attractive total remuneration package is offered \\
\hline REM2 & Above average wages are offered \\
\hline
\end{tabular}


particularly to those aspects that are relevant to the target of interest, then branding does not fulfil its "reason d'être". The modern competitive environment and the growing demands for skilled and talented employees and executives in the market, is forcing companies to seek a way to prevail as employers over other organizations and to increase their competitiveness, without sacrificing their distinctive identity (Kucherov, Zavyalova 2012; Rampl 2014).

Since, as Backhaus and Tikoo (2004) argue, EBing proposes differentiation of a firm's characteristics as an employer from those of its competitors, a company should try to find the appropriate way to create a unique identity and become an attractive employer to its most valuable employees. In discussing EBs, this piece of research demonstrates that employees particularly value the distinctiveness of the organisation to which they relate (Dutton et al. 1994). Hence, the multi-dimensionality of the ideal employer construct, the EB of Choice, carries interesting implications for companies willing to invest in their EB. First, they must realise that the EB permeates the entire "experience" of the employees, from recruitment and entry to exit from the relationship. This is particularly important in the case of the EB of Choice, since the expectations of the employees from such a brand are high. Along these lines, the EB of Choice has to keep the employment and work experience constantly favourable as this experience is reflected to psychological as well as to functional benefits of the company brand. Managers of the EB of Choice should not underestimate the fact that when these expectations are met, then the generated satisfaction increases, ensuring to the company loyalty, positive referrals and constructive networking among the different stakeholders. It is therefore hardly surprising that, as demonstrated in the EB of Choice dimensions, quite a number of the associated characteristics are related to decisions that have to be made by the senior management of an organisation. Consequently, the EB of Choice should be seen as a strategic issue with a long term perspective and should not be treated as a tactical issue or a communication exercise. In effect, it is this multi-dimensionality of benefits and characteristics that our empirical study reveals that calls for the acquisition and exercise of a variety of skills and deployment of resources that are required in an organisation that departs to meet prospective and present employee expectations. These employee demands should act as a mechanism driving the company towards continuous internal and external distinctiveness in order to enhance its competitive advantage. After all, this ability of the company to differentiate itself, not only through superiority in its product markets, but also in the "labour" markets can be better developed by constantly building its personality along the attributes of an EB of Choice. When the ability of a company to differentiate itself as an employer results in attracting talented and eager to develop employees, the former has earned the opportunity to transform them into satisfied and loyal organizational members.

Given the fact that EBing efforts aim at differentiating the employment experience that an organisation offers to its current and potential employees, organisations need to offer an attractive package of benefits and characteristics that outperform those of other organisations. Bearing into consideration the fact that every company has only limited resources, the ability to recognise what is important can help the company prioritize employee-based programs. In conclusion, the practical success of an EB of Choice depends on creating and offering applicants and employees a realistic and viable external and internal brand proposition. 


\section{Conclusions}

If we had to summarise the dimensions sought in one word, "investment" would be an appropriate one as employees appreciate, and therefore "vote" for those companies that seeks for competitiveness not only for their product brand but also for their EB. Apparently, many aspects of EB of Choice do not relate to financial strength or position in the market. Benefits that are incorporated in the Recognition and Relationships groups of benefits are actually culture-driven, while others are incorporated in the Selfdevelopment dimension, and are attitudinal and value-driven. Overall, creating an EB of Choice necessitates being proactive rather than reactive and incorporating its core components in the DNA of the organisation.

In order to place the study in its scientific context, a number of limitations could be noted. First of all, the particular study does not allow for an assessment of the relative importance of each of the benefits or characteristics incorporated in the model. This limitation becomes relevant when resources are particularly restricted. However, as the results indicate, management has quite an array of culture related (and not costly) tools at its disposal in the effort to create an EB of Choice. Focusing on further research, the topic of EB of Choice could be examined on a comparative basis (between successful and unsuccessful EBs of Choice). Additionally, emphasis could be given on the delineation of the relative importance of the EB of Choice dimensions, as well as longitudinal and national investigations (Almacik et al. 2014). Moreover, based on evidence in differences on the EB of Choice profile based on gender (Bellou et al. 2015), key personality traits and characteristics could also be examined. Finally, the new organization reality that has emerged in several countries due to financial crisis (Gogolova 2015), indicates the need to further investigate the EB agenda.

\section{References}

Aaker, D. A. 2003. Brand portfolio strategy: creating relevance, differentiation, energy, leverage, and clarity. New York, NY: The Free Press.

Almacik, E.; Almacik, U.; Erat, S.; Akcin, K. 2014. Attracting talented employees to the company: do we need different employer branding strategies in different cultures?, Procedia - Social and Behavioural Sciences 150: 336-344. http://dx.doi.org/10.1016/j.sbspro.2014.09.074

Ambler, T.; Barrow, S. 1996. The employer brand, The Journal of Brand Management 4(3): 185-206. http://dx.doi.org/10.1057/bm.1996.42

Ashforth, B. E.; Harrison, S. H.; Corley, K. G. 2008. Identification in organisations: an examination of four fundamental questions, Journal of Management 34(3): 325-74.

http://dx.doi.org/10.1177/0149206308316059

Backhaus, K.; Tikoo, S. 2004. Conceptualizing and researching employer branding, Career Development International 9(4/5): 501-517. http://dx.doi.org/10.1108/13620430410550754

Barrow, S.; Mosley, R. 2005. The employer brand - bringing the best of brand management to people at work. Hoboken, $\mathrm{NJ}$ : Wiley.

Bellou, V. 2007. Psychological contract assessment after a major organisational change the care of mergers and acquisitions, Employment Relations 29(1): 68-88.

http://dx.doi.org/10.1108/01425450710714487 
Bellou, V.; Rigopoulou, I.; Kehagias, I. 2015. Employer of choice: does gender matter?, Gender in Management: an International Journal 30(8): 613-634.

http://dx.doi.org/10.1108/GM-01-2015-0004

Berthon, P.; Ewing, M.; Hah, L. L. 2005. Captivating company: dimensions of attractiveness in employer branding, International Journal of Advertising 24(2): 151-172.

Branham, L. 2005. Planning to become an EOC, Journal of Organisational Excellence 24(3): 57-68. http://dx.doi.org/10.1002/joe.20060

Conference Board. 2001. Engaging employees through your brand. New York: The Conference Board.

Davies, G. 2008. Employer branding and its influence on managers, European Journal of Marketing 42(5/6): 667-681. http://dx.doi.org/10.1108/03090560810862570

Davies, G. J.; Chun, R.; Da Silva, R.; Roper, R. 2004. A corporate character scale to assess employee and customer views of organisation reputation, Corporate Reputation Review 7(2): 125-46. http://dx.doi.org/10.1057/palgrave.crr.1540216

Davies, G. J.; Chun, R.; Kamins, M. A. 2010. Reputation gaps and the performance of service organizations, Strategic Management Journal 31: 530-546.

de Chernatony, L.; Dall'Olmo Riley, F. 1999. Experts views about defining services brands and the principles of services branding, Journal of Business Research 46(2): 181-92.

http://dx.doi.org/10.1016/S0148-2963(98)00021-6

Dutton, J. E.; Dukerich, J. M.; Harquail, C. V. 1994. Organisational images and member identification, Administrative Science Quarterly 39: 239-63. http://dx.doi.org/10.2307/2393235

Edwards, M. R. 2009. An integrative review of employer branding and OB theory, Personnel Review 39(1): 5-23. http://dx.doi.org/10.1108/00483481011012809

Edwards, M. R.; Edwards; T. 2013. Employee responses to changing aspects of the employer brand following a multinational acquisition: a longitudinal study, Human Resource Management 52: 27-54. http://dx.doi.org/10.1002/hrm.21519

Elving, W. J. L.; Westhoff, J. J. C.; Meeusen, K.; Schoonderbeek, J. W. 2013. The war for talent? The relevance of employer branding in job advertisements for becoming an employer of choice, Journal of Brand Management 20: 355-73. http://dx.doi.org/10.1057/bm.2012.21

Fernandez-Lores, S.; Gavilan, D.; Avello, M.; Blasco, Fr. 2015. Affective commitment to the employer brand: development and validation of a scale, Business Research Quarterly.

http://dx.doi.org/10.1016/j.brq.2015.06.001

Gogolova, M. 2015. The impact of financial crisis on the labout protection of chosen employer brands in the construction industry in Slovakia, Procedia Economics and Finance 23: 1434-1439. http://dx.doi.org/10.1016/S2212-5671(15)00458-X

Hair, J. F.; Black, W. C.; Babin, B. J.; Anderson, R. E. 2009. Multivariate data analysis. Upper Saddle River, NJ: Prentice Hall.

He, H.-W.; Balmer, J. M. T. 2013. A grounded theory of the corporate identity and corporate strategy dynamic: a corporate marketing perspective, European Journal of Marketing 47(3/4): 401-30. http://dx.doi.org/10.1108/03090561311297391

Herman, R. E.; Gioia, J. L. 2000. How to become an EOC. Naperville, IL: Oak Hill Publishing Company.

Hochegger, S.; Terlutter, R. 2012. Why organizations systematically engage in employer branding: a conceptual framework, Advances in Advertising Research 3: 403-419.

http://dx.doi.org/10.1007/978-3-8349-4291-3_31

Hoyle, R. H.; Panter, A. T. 1995. Writing about structural equation models, in R. H. Hoyle, Structural equation modelling: concepts, issues, and applications. Newbury Park, CA: Sage. 
Jain, N.; Bhatt, Pr. 2014. Employment preferences of job applicants: unfolding employer branding determinants, Journal of Management Development 34(6): 634-652.

http://dx.doi.org/10.1108/JMD-09-2013-0106

Kapferer, J. 2004. The new strategic brand management: creating and sustaining brand equity long term. London: Kogan Page.

Kidder, D. L. 2002. The influence of gender on the performance of organisational citizenship behaviours, Journal of Management 28(5): 629-48. http://dx.doi.org/10.1177/014920630202800504

Knox, S.; Freeman, C. 2006. Measuring and managing employer brand image in the service industry, Journal of Marketing Management 22(7): 695-716.

http://dx.doi.org/10.1362/026725706778612103

Koberg, S. C.; Chusmir, L. H. 1987. Organisational culture relationships with creativity and other job-related variables, Journal of Business Research 15: 397-409.

http://dx.doi.org/10.1016/0148-2963(87)90009-9

Kucherov, D.; Zavyalova, E. 2012. HRD practices and talent management in the companies with the employer brand, European Journal of Training and Development 36(1): 86-104.

http://dx.doi.org/10.1108/03090591211192647

Lievens, F. 2007. Employer branding in the Belgian army: the importance of instrumental and symbolic beliefs for potential applicants, actual applicants, and military employees, Human Resource Management 46(1): 51-69. http://dx.doi.org/10.1002/hrm.20145

Lievens, F.; Hoye van, G.; Anseel, F. 2007. Organisational identity and employer image: towards a unifying framework, British Journal of Management 18: 45-59.

http://dx.doi.org/10.1111/j.1467-8551.2007.00525.x

Mangold, W. G.; Miles, S. J. 2007. Growing the employee brand at ASI, Journal of Leadership \& Organisational Studies 14(1): 77-85. http://dx.doi.org/10.1177/1071791907304287

Montes, S. D.; Zweig, D. 2009. Do promises matter? An exploration of the role of promises in psychological contract breach, Journal of Applied Psychology 94(5): 1243-60.

http://dx.doi.org/10.1037/a0015725

Mosley, R. W. 2007. Customer experience, organisational culture and the employer brand, Brand Management 15(2): 123-34. http://dx.doi.org/10.1057/palgrave.bm.2550124

O’Reilly, C. A. III; Chatman, J.; Caldwell, D. F. 1991. People and organisational culture: a profile comparison approach to assessing person-organisation fit, The Academy of Management Journal 34(3): 487-516. http://dx.doi.org/10.2307/256404

Rampl, L. V. 2014. How to become an employer of choice: transforming employer brand associations into employer first-choice brands, Journal of Marketing Management 30(13-14): 1486-1504. http://dx.doi.org/10.1080/0267257X.2014.934903

Rampl, L. V.; Kenning, P. 2014. Employer brand trust and affect: linking brand personality to employer brand attractiveness, European Journal of Marketing 48(1/2): 218-236.

http://dx.doi.org/10.1108/EJM-02-2012-0113

Rousseau, D. M. 1989. Psychological and implied contracts in organisations, Employee Responsibilities and Rights Journal 2(2): 121-39. http://dx.doi.org/10.1007/BF01384942

Schumacker, R. E.; Lomax, R. G. 2004. A beginers guide to structural equation modelling. $2^{\text {nd }}$ ed. Mahwah, NJ: Laurence Erlbraum Associates.

Slaughter, J. E.; Zickar, M. J.; Highhouse, S.; Mohr, D. C. 2004. Personality trait inferences about organisations: development of a measure and assessment of construct validity, Journal of Applied Psychology 89: 85-102. http://dx.doi.org/10.1037/0021-9010.89.1.85

Sutherland, M. M.; Torricelli, D. G.; Karg, R. F. 2002. Employer-of-choice branding for knowledge workers, South African Journal of Business Management 33(4): 13-20. 
Tajfel, H.; Turner, J. C. 1986. The social identity theory of intergroup behaviour, in S. Worchel, W. G. Austin (Eds). Psychology of intergroup relations. $2^{\text {nd }}$ ed. Chicago: Nelson - Hall, 7-24.

Tomlinson, G. 2010. Building a culture of high employee engagement, Strategic HR Review 9(3): 25-31. http://dx.doi.org/10.1108/14754391011040046

Wilden. R.; Gudergan, S.; Lings, I. 2010. Employer branding: strategic implications for staff recruitment, Journal of Marketing Management 26(1/2): 56-73.

http://dx.doi.org/10.1080/02672570903577091

Williams, M. 2000. The war for talent. London: The Chartered Institute of Personnel and Development.

Victoria BELLOU is an Assistant Professor at the University of Thessaly, Greece. She has gained her Bachelor's degree at the University of New Haven, CT, USA, her Master's at the University of Macedonia, Greece, and her PhD at the University of Piraeus, Greece. She has professional experience as Human Resource Specialist and has worked on several research projects. Her research interests include psychological contract, organisational culture, public sector management, service quality and management of change.

Ioannis E. CHANIOTAKIS is Head of the Savings and Investment Products Division in Piraeus Bank. He has been Tutor of Marketing in the Hellenic Open University and in the University of the Aegean. He holds a BSc in Agricultural Economics from the Aristotle University of Thessaloniki, an $\mathrm{MSc}$ in Marketing from the University of London and a $\mathrm{PhD}$ in Marketing from the University of the Aegean. He has worked for Nestle and ATEbank. He is the author of several articles in international scientific journals and conferences. His research interests are consumer behaviour, services marketing, and food marketing.

John KEHAGIAS is Associate Professor at the Hellenic|Open University. He has also taught at the University of the Aegean and the University of Piraeus. Before joining the University he worked in senior marketing positions for large Greek and international companies. His research interests revolve around international marketing, pricing and the marketing-human resources management interface.

Irini RIGOPOULOU is an Assistant Professor of Marketing at Athens University of Economics and Business. She holds a PhD in Marketing from the Aegean University, Greece. She worked for multinational and national companies in Greece. She is the author of several articles in international scientific journals and conferences. Her research interests are, among others, brand marketing and e-marketing. 